La primavera que no fue: el gobierno de Roberto Heredia en Tres de Febrero, 1973- 1975

Luciana Mingrone

páginas / año 13 - n 31 Enero - Abril / ISSN 1851-992X/ 2021

http://revistapaginas.unr.edu.ar/index.php/RevPaginas

DOI: http://dx.doi.org/10.35305/rp.v12i30.464

\title{
La primavera que no fue: el gobierno de Roberto Heredia en Tres de Febrero, 1973- 1975
}

\section{The springtime that was not: the government of Roberto Heredia in Tres de Febrero, 1973-1975}

\author{
Luciana Mingrone \\ Universidad Nacional Tres de Febrero (Argentina) \\ lucianamingrone@gmail.com
}

\begin{abstract}
Resumen
Este trabajo aborda el período de gobierno municipal de Roberto Heredia en un distrito del primer cordón del conurbano bonaerense. La intendencia de Heredia fue atravesada por un conflicto interno del peronismo que se intentó presentar como un choque ideológico entre los sectores tradicionales de ese partido y Montoneros. Ningún militante de esa organización armada integraba la composición electoral o el elenco de gobierno de Heredia, pero dos concejales (uno titular y otra, suplente) eran parte de otra organización: el Movimiento Revolucionario 17 de octubre. Es por eso que este artículo, además de intentar contribuir a conocer más profundamente el período en general, también ahonda en la historia de ese espacio a nivel nacional y local.
\end{abstract}

Palabras Clave

Peronismo; MR17; conflictos internos; Montoneros; peronismo revolucionario.

\begin{abstract}
This work addresses the period of municipal government of Roberto Heredia in a district of the área closest to Buenos Aires city in the province suburbs. That administration was convulsed by an internal conflict of Peronism that was tried to be shown as an ideological clash between the traditional sectors of that party and Montoneros. Nobody of that armed organization was part of Heredia's electoral composition or cast, but two councilors (one incumbent and one alternate) were part of another organization: Movimiento Revolucionario 17 de octubre (MR17). That's the reason why this article also delves into the history of that space at the national and local levels.
\end{abstract}

\section{Keywords}

Peronism; MR17; internal conflicts; Montoneros; revolutionary wing of peronism. 


\section{Luciana Mingrone}

\section{Introducción}

"Yo, en mi recuerdo, lo tengo como 'el intendente montonero'". Así evocó un vecino de la zona a Roberto Manuel Heredia, intendente de Tres de Febrero ${ }^{1}$ entre el 25 de mayo de 1973 y el 10 de agosto de 1975, cuando -tras una larga serie de acusaciones y disputas- fue destituido. A pesar de esa cristalización en el imaginario popular de su figura, Heredia era militante peronista desde el origen del movimiento y estaba lejos de Montoneros. Pero, ¿por qué Heredia quedó instalado en la memoria con una caracterización que no reflejaba su identidad política?

Lo que resulta más obvio es que el ex intendente quedó impregnado en la memoria colectiva con cierta afinidad a la organización, en parte, porque fue elegido como candidato del Frente Justicialista de Liberación (FREJULI), la alianza electoral que el Partido Justicialista construyó junto a otros espacios, llevó a Héctor Cámpora a la presidencia e incluyó representantes de Montoneros en diversos poderes ejecutivos y legislativos. Además, el hecho de que haya existido un conflicto interno que terminó con la destitución de Heredia contribuyó a emparentar el caso local con otros gobiernos contemporáneos que también se vieron envueltos en reyertas pero que, en general, tuvieron que ver -justamente- con la presencia en ellos de militantes montoneros. En el caso de Tres de Febrero no parece corroborarse esa naturaleza del conflicto, ya que el mismo se limitó a una disputa entre sectores del peronismo tradicional en los que prácticamente no intervinieron Juan Carlos Sandoval ni Josefina Elvira Thomspon, ${ }^{2}$-los únicos representantes de sectores juveniles en la lista que encabezó Heredia- que no eran militantes montoneros.

En estas particularidades de Tres de Febrero reside el interés por abordar el período que va desde el Gran Acuerdo Nacional hasta 1975 y obligan a elaborar algunas precisiones sobre la escala de análisis elegida. Este artículo no pretende ser un "estudio de caso" que trasplante los análisis nacionales al ámbito distrital, sino una exploración sobre el tema situada en el partido, desde la convergencia de las dimensiones locales y nacionales, tanto en la coyuntura como en las problemáticas de larga data. El objetivo principal de este artículo es enriquecer y complejizar los estudios del período a partir de dos ejes: el conflicto en el que se vio envuelto el gobierno de Heredia y la Juventud Peronista local. El trabajo se organiza a partir de esos ejes: en la primera parte, se analiza el contexto de la llegada al poder de Heredia en una sección y, en otra, el conflicto que termina con su dimisión. En una segunda parte, dos segmentos abordan la cuestión de la JP local: uno en la que se estudia la organización del concejal Sandoval y otro en el que se vinculan las expresiones locales del MR17 y de Montoneros.

\footnotetext{
1 Tres de Febrero es un distrito del Noroeste del primer cordón del Conurbano bonaerense, que nace en 1960 al hacerse efectiva su separación del municipio de San Martín.

${ }^{2}$ Ambos fueron víctimas del terrorismo de Estado, los restos de Josefina Elvira Thompson fueron identificado s por el EAAF en 2009. Juan Carlos Sandoval, su hermano Pedro y la esposa de éste, Liliana Fontana, fueron secuestrados cuando ella estaba embarazada. Su hijo fue intensamente buscado por la mamá de Liliana (Clelia Deharbe) y toda la familia y su identidad restituida en 2006. Liliana, Juan Carlos y Pedro Sandoval forman parte de la lista de desaparecidos.
} 


\section{La primavera que no fue: el gobierno de Roberto Heredia en Tres de Febrero, 1973- 1975}

Sucesos similares a los que terminaron con la caída de Heredia afectaron a otros gobiernos municipales en Lomas de Zamora, San Isidro, Coronel Pringles, Ramallo, San Nicolás, 25 de mayo, Junín, Tres Arroyos, Pergamino y Zárate (Antúnez, 2015). También en escenarios provinciales se manifestaron estas disputas. Formosa, Córdoba, Mendoza, Santa Cruz y Salta fueron intervenidas por el Poder Ejecutivo nacional entre noviembre de 1973 y noviembre de 1974 y Oscar Bidegain, gobernador de Buenos Aires, fue obligado a renunciar.

La producción académica sobre el tercer gobierno peronista puede clasificarse en dos perspectivas. Una hace hincapié en el enfrentamiento violento entre la Tendencia Revolucionaria del Peronismo y los sectores tradicionales del partido como principal obstáculo para el desenvolvimiento natural de la institucionalidad política (De Riz, 1981; Gillespie, 1987). Marina Franco también estudia el período atendiendo a la espiral de violencia desencadenada en la época, pero subraya especialmente la política "antisubversiva" del tercer gobierno peronista como eje de esa virulenta relación entre sectores diversos (Franco, 2012). Otro abordaje de los antagonismos del período 1973- 1976 corre el foco del enfrentamiento violento y los lee como resultado de la confluencia entre elementos coyunturales y conflictos de larga data muchas veces vinculados con la dinámica propia de cada provincia (Servetto, 2010). El caso de Tres de Febrero parece abonar a esta corriente, ya que la institucionalidad municipal no se vio afectada por el accionar violento de los protagonistas, aunque, en definitiva, el resultado fue el mismo: entre 1973 y 1975 la localidad prácticamente no tuvo gestión municipal. Pero, además, el caso presenta otra particularidad ya que ningún sector de la JP intervino en el conflicto. En este sentido, el ejemplo local complejiza la tradicional mirada sobre el tema que reduce el enrarecido clima político de la etapa estudiada al enfrentamiento violento entre la Tendencia Revolucionaria del Peronismo y el resto del movimiento.

Los orígenes de la Juventud Peronista han sido rastreados en los primeros gobiernos peronistas (Acha, 2011) y su devenir posterior a 1955 también ha sido reconstruido por la bibliografía académica (Ehrlich, 2012). Hacia 1971, el clima de época revitalizó la agrupación que ganó el protagonismo propio de la renovación generacional que caracterizó a las décadas de 1960 y 1970. Pero fue en 1972 cuando Montoneros transformó a la agrupación en su principal herramienta de inserción territorial tras la conformación de la Juventud Peronista (Regionales), nombre que obedecía a su estructura dividida primero en siete y luego en ocho áreas geográficas. La ya clásica obra sobre Montoneros del autor británico Richard Gillespie identificó como la "etapa movimientista" de la organización la abierta a principios de 1973 cuando Montoneros dejó de limitar su trabajo "de superficie" a la Juventud Peronista (Regionales) para conformar la Tendencia Revolucionaria del Peronismo, aglutinar bajo ese paraguas otros frentes de masas tales como la Juventud Universitaria Peronista o la Juventud Trabajadora Peronista y participar en la conformación del entramado electoral y los elencos de la administración pública constituidos después del triunfo de marzo de 1973 (Gillespie, 1987: 198- 202). 


\section{Luciana Mingrone}

La experiencia de la Juventud Peronista tresfebrerense puede sugerir algunas explicaciones complementarias para aquel análisis clásico, ya que -como se dijo- los representantes de los sectores juveniles que participaron en la experiencia electoral eran militantes del MR17, al tiempo que los miembros de Montoneros privilegiaron su militancia territorial antes que la activación en los ámbitos legislativos o ejecutivos. Es posible pensar, entonces, que la estrategia de la integración institucional no fue una generalizada en todos los lugares en los que Montoneros tuvo desarrollo y que, a su vez, esa integración dependió de la acción de diversos actores involucrados en la JP.

En este sentido, debemos dar alguna precisión sobre cómo habrán de abordarse las trayectorias de los militantes de las agrupaciones juveniles mencionadas. En este trabajo no se utiliza la historia de vida como metodología, pero sí se hace alusión a los itinerarios personales de algunos miembros de la JP local con el propósito de entender sus procesos de politización (Chama y González Canosa, 2018), es decir, el modo en que estos actores sociales insertaron sus demandas en dos proyectos políticos (el del MR17 y el de Montoneros) que, como veremos, tuvieron intersecciones en su activación social y su radicalización, pero no en su ideario ni en su programa político.

Para cada uno de esos dos proyectos la periodización implementada para su comprensión es diferente. En el caso del MR17, además de atender especialmente su devenir en la etapa abierta tras el GAN, se analizará su nacimiento en 1970 y atenderemos a algunas cuestiones del período en el que se gesta dentro del Movimiento Revolucionario Peronista (1964- 1970). En el caso de Montoneros, abordaremos tres etapas: las militancias previas al nacimiento de la organización a nivel local (1969-1972), la de la articulación de diferentes experiencias como el origen propiamente dicho de Montoneros en el distrito (1972) y la etapa contemporánea al inicio del gobierno de Heredia (1973).

Cabe agregar que para abordar la relación entre la militancia local del MR- 17 y la de Montoneros es clave repensar los resortes socio-culturales de esos procesos de politización, es decir, el concepto de sociabilidad que muchos autores han retomado desde la resignificación de las tradiciones contractualistas de los siglos XVII y XVIII ofrecida por el francés Maurice Agulhon, para subrayarlo como un elemento especialmente importante en el estudio de las prácticas políticas de las "juventudes" de la década de 1960 y 1970 (Ehrlich, 2012; González Canosa y Murphy, 2019). Entendiendo la sociabilidad como el conjunto de relaciones propias de ese dominio intermedio entre la familia y la comunidad nacional, el concepto es fundamental para dar cuenta de intereses, pertenencias e identificaciones políticas para los que no basta con entender elementos ideológicos, si no también emocionales y afectivos. Lucas Lanusse, en su esclarecedor estudio sobre el origen de Montoneros usó los conceptos de ámbito, círculo y grupo para explicar las conexiones sociales claves de las prácticas políticas de los "proto-montoneros" (Lanusse, 2005, pp. 184- 196). Sin embargo, los mecanismos sociales y culturales de la acción política que pueden restituirse a partir de las experiencias de la militancia tresfebrerense podrían ser 


\section{La primavera que no fue: el gobierno de Roberto Heredia en Tres de Febrero, 1973- 1975}

representados como una amplia e intrincada red en la que se cruzan tradiciones diversas y una cantidad de espacios de sociabilidad y militancia que van desde centros de estudiantes de escuelas secundarias hasta grupos de boy scouts. Otros estudios a pequeña escala han renovado la historiografía sobre las trayectorias y los procesos de politización de las juventudes de la época para observar en los orígenes locales de Montoneros la construcción de una compleja trama constituida por espacios muy diversos como, en el caso de La Plata, espacios de militancia barrial (Robles, 2009), en el caso de Moreno, la Asociación Obrera Textil o el Centro de Operaciones de la Resistencia (Salcedo, 2011), en Rawson, el sindicato de trabajadores de la administración pública (González Canosa y Murphy, 2019) y en Mar del Plata diversas organizaciones de la militancia estudiantil (Pozzoni, 2008 y Bartolucci, 2017). Pero, además del complejo entramado que dio origen a Montoneros en el distrito, hay que adelantar que en la investigación sobre las experiencias locales de esa organización y del MR-17, la militancia de ambos espacios habrá de relacionarse en una amplia red no solo durante la gestación de las organizaciones (entre fines de la década de 1960 y 1971), sino también en la etapa 1972- 1974.

Finalmente, una última aclaración hermenéutica es necesaria y tiene que ver con el modo en que nos referiremos a cada una de las organizaciones juveniles abordadas en este estudio. La literatura académica ya ha reflexionado sobre la utilidad interpretativa del concepto "izquierda peronista" para generalizar a aquellas experiencias (armadas o no) que, desde 1955 y especialmente en las dos décadas posteriores, combinaron posturas anticapitalistas con la adhesión a la identidad política peronista (Caruso, Campos, Vigo, Acha; 2017). Justamente por esas indicaciones usaremos "izquierda peronista" para referirnos al conjunto de esas agrupaciones (en nuestro caso, Montoneros y MR-17) reconociendo su carácter politético, es decir, asumiendo que definimos con una misma categoría a experiencias diferentes. Cuando se haga referencia al MR-17 se los identificará a partir de su vinculación con la primera Tendencia Revolucionaria o con la categoría "peronismo revolucionario", ya que en esos términos se reconoció a sí misma la organización.

En el caso de Montoneros, la cuestión de su identidad política es un tema que excede ampliamente los límites de este trabajo y que ya se ha analizado (Slipak, 2015, entre otros). Si debiéramos usar para Montoneros también la forma en que se autodefinió, tal cosa sería imprecisa y no tendría sustento histórico, ya que la organización ensayó una genealogía atada a la Resistencia Peronista que estuvo lejos de corresponderse con lo que se ha sustentado empíricamente. De los muchos caminos que confluyeron en la organización, la mayor parte de los miembros originarios de Montoneros en Tres de Febrero habían iniciado sus trayectorias en espacios vinculados de una u otra forma con el cristianismo renovado, por lo que usaremos esa identificación para dar precisión al objeto de estudio. En buena medida, los vaivenes de esos recorridos serán parte del análisis a desarrollar. Con tal fin, se ha trabajado con testimonios de algunos de los protagonistas y un corpus que no 


\section{Luciana Mingrone}

incluye documentos oficiales del municipio (material que no está disponible), pero sí fuentes periodísticas locales.

\section{Primera parte: de la primavera al ocaso}

\section{El camino a las elecciones de 1973}

El 31 de mayo de 1972 el presidente de facto Alejandro Lanusse presentó las características del GAN, el proceso de apertura democrática que terminaría en las elecciones de marzo del año siguiente. Aunque tal acuerdo conllevó al fin de la proscripción del peronismo, la obstrucción de la candidatura de Juan Domingo Perón le confirió al proceso de construcción electoral del justicialismo aún más complejidad de la determinada por 18 años de exclusión legal del juego político. Quién había sido nombrado delegado de Perón en 1968, Jorge Daniel Paladino, inició el proceso de normalización del Movimiento Nacional Justicialista a través de la organización de una serie de "Juntas Promotoras". El reemplazo de Paladino por Héctor Cámpora como delegado nacional hizo que el mismo se pusiera a la cabeza del "Comando táctico" que cumpliría la directiva de Perón de reorganizar el movimiento y, especialmente, su rama política: el Partido Justicialista (Ladeuix, 2005).

En ese contexto, a principios de 1972 Perón llamó a conformar el Frente Cívico de Liberación Nacional, una herramienta de acumulación política mayor que la de la Hora del Pueblo, la alianza política que había logrado un amplio consenso de partidos tradicionales desde 1970. La indicación de Perón fue conformar listas únicas, tal operación fue un intento por "diferir la discusión de una 'actualización doctrinaria' permeada de matices izquierdizantes" (Bozza, 1997:146). Aunque se intensificó el uso de los tópicos del peronismo revolucionario, la alianza con el desarrollismo y la perspectiva europeísta fueron algunos de los elementos que limitaron el debate ideológico a lo meramente discursivo.

Sin embargo, la alianza pre-electoral más amplia y equilibrada que conformaba el FRECILINA empezó a corroerse en junio durante el congreso nacional del PJ en el que se eligieron las autoridades partidarias (asientos que no fueron ocupados por representantes de la rama sindical pero sí por sectores juveniles cercanos a Montoneros) y se optó por la candidatura a presidente de Perón. La posterior inclusión de una cláusula que impedía esa opción hizo que el candidato fuera quién había sido nombrado dos meses antes vicepresidente segundo del partido: Héctor Cámpora. Como reacción al obstáculo de la normativa de Lanusse a la candidatura de Perón, se inició la campaña "Luche y vuelve", en la que los sectores juveniles y, particularmente, Montoneros ganaron protagonismo. El 17 de noviembre de 1972, Perón regresó a Buenos Aires por dos meses para organizar la que finalmente sería la alianza que se presentaría a las elecciones de marzo: el Frente Justicialista de Liberación (FREJULI) 


\section{La primavera que no fue: el gobierno de Roberto Heredia en Tres de Febrero, 1973- 1975}

$\mathrm{Al}$ interior de la estructura partidaria, el cierre de ese proceso de armado electoral fue el Congreso de Avellaneda en diciembre de 1972, en el que se pretendió normalizar el PJ bonaerense y elegir como candidatos para el gobierno provincial a los señalados por Perón, Oscar Bidegain y René Orsi. Pero la presión del sindicalismo (especialmente de la UOM) por proclamar la candidatura de Manuel de Anchorena y Luis Guerrero hizo que estallara la violencia y la elección se pospusiera hasta que, por fin, en enero de 1973 se conoció que los candidatos a gobernador y vicegobernador de la provincia serían Bidegain y Victorio Calabró, un opositor al metalúrgico Lorenzo Miguel.

Perón mantuvo la premisa de conformar listas únicas e indicó que las mismas debían equilibrarse entre los sectores de la rama política, la sindical, la juventud y los aliados extrapartidarios. La construcción de estos elencos fue un proceso tumultuoso que en algunos distritos bonaerenses no se saldó sin elecciones internas y que incluyó, también, la decisión de intervenir esas instancias distritales del PJ por parte de Juan Manuel Abal Medina, Secretario General del Movimiento Nacional Justicialista y, aunque hermano de uno de los fundadores de Montoneros, cercano a los sectores nacionalistas de las Fuerzas Armadas.

Como se vio, el contexto previo a las elecciones de marzo de 1973 es el del complejo proceso de normalización del Partido Justicialista en el que Perón pretendió equilibrar fuerzas entre los sectores tradicionales del peronismo y transformar a los sectores juveniles, que desde 1970 habían optado por la lucha armada, en apenas "formaciones especiales" de la estructura partidaria. Tal cosa fue imposible y el resultado fue que no sólo en algunos distritos como Mar del Plata, Necochea o Suipacha el peronismo perdió las elecciones por no poder consensuar una lista única, si no que en muchos otros los conflictos internos siguieran aun cuando ya habían resultado ganadores los candidatos peronistas y ocupaban las intendencias de los distrititos.

Dada la juventud de la localidad, la clase política y el desarrollo económico de Tres de Febrero, para la década de 1970, todavía estaban atados a San Martín. Entre su creación y el Onganiato, el distrito había tenido dos intendentes democráticos: Ramón Landini y Roberto D’Elia, ambos del Movimiento de Integración y Desarrollo (MID). Las intervenciones de la "Revolución Argentina" habían dado como resultado gobiernos municipales inestables. Para 1973 el interventor era Arturo Bombelli también desarrollista- quién entre principios de 1972 y el fin de su gobierno, solicitó reiterados pedidos de licencia y fue reemplazado en varias oportunidades por el propio D’Elía, entonces secretario de gobierno.

Los años de proscripción habían sido de poca actividad para el peronismo local que, en 1972, en el marco de la apertura electoral, convocó a elecciones internas para elegir sus autoridades. La prensa local planteaba como posibles candidatos a Luis Moreno, Pedro Gallo, al ex diputado Maximino Castillo, y dos dirigentes sindicales: Millán del Sindicato del Vidrio y Alejandro Caro, secretario de la UOM en la seccional Ciudadela. Finalmente, el triunfador fue Pedro Gallo. Para elegir el candidato a intendente también hubo internas entre Milán, apoyado por las autoridades de una 


\section{Luciana Mingrone}

emblemática institución de la zona -el Banco Cooperativo de Caseros-, y la candidatura sostenida por Castillo (que volvería a ser diputado), su cuñado y futuro concejal Juan Carlos Rodríguez, y Rubén Novoa que promovieron a Roberto Heredia, quién terminó por imponerse. ${ }^{3}$

Heredia había comenzado su militancia política justamente en San Martín, luego de haber sido testigo de las movilizaciones del 17 de octubre de 1945 que lo decidieron a enrolarse en las filas de lo que más tarde sería el Partido Justicialista. Había aprendido el oficio de panadero en su juventud y para 1973 regenteaba una panadería en la calle Perdiguero en la localidad de Caseros. Su militancia en el justicialismo no había cesado e, inclusive, en 1965 había sido concejal de la Unión Popular, identidad con la que se presentó a elecciones el peronismo proscripto. ${ }^{4}$

\section{Heredia: de las acusaciones a la destitución}

Roberto Heredia llegó al poder de Tres de Febrero como cabeza de lista de una particular constitución de fuerzas que incluía al partido que había dominado la política municipal durante toda la década del 60 (el MID), el que tenía mayor atracción popular (el PJ), representantes del sindicalismo local y dos exponentes del Movimiento Revolucionario 17 de octubre. En este apartado se analizará el desarrollo del conflicto que terminó con la dimisión de Heredia.

En junio de 1973, Perón regresó definitivamente al país. En esas circunstancias, se evidenció no sólo el enfrentamiento entre los sectores reaccionarios del peronismo y Montoneros, si no la evidente toma de posición en esa disputa por parte del viejo líder. Esas disputas recrudecieron cuando el 25 de septiembre de 1973 fue asesinado el líder de la CGT, José Ignacio Rucci. El 2 de octubre, el diario La Opinión hizo público un documento interno del Consejo Nacional del Partido Justicialista que instaba a la depuración ideológica del movimiento, llamando a perseguir la "infiltración marxista" con la que se identificaba claramente a Montoneros. Además de este dispositivo intra- partidario, fueron otros los mecanismos legales que durante el interregno Lastiri y la tercera presidencia de Perón se desplegaron para restar poder a Montoneros en los diferentes espacios políticos que la organización pretendía ocupar. La ley de Asociaciones Profesionales o la de Prescindibilidad son algunos ejemplos. Pero, especialmente después del asesinato de Rucci, esas estrategias legales se combinaron con una fuerte represión a manos de funcionarios y agentes de fuerzas de seguridad, que luego formarían la Asociación Anticomunista Argentina. Asimismo, diferentes organizaciones nacionalistas ligadas al peronismo, grupos sindicales y cuadros de la derecha peronista como el Comando de Organización, la Agrupación 20 de noviembre o la Concentración Nacionalista Universitaria participaron de la "cruzada" contra Montoneros (Merele, 2017).

\footnotetext{
${ }^{3}$ Máximo Rodríguez en entrevista con la autora, julio 2020.

${ }^{4}$ Cristina Heredia en entrevista con la autora, mayo 2013.
} 


\section{La primavera que no fue: el gobierno de Roberto Heredia en Tres de Febrero, 1973- 1975}

Apenas ocho días después de la asunción de Heredia, El Municipal (una publicación asociada a la Lista Verde del sindicalismo municipal) advertía sobre la incógnita que se abría alrededor de la orientación del nuevo gobierno dada la "heterodoxia de la lista del FREJULI" tan diferente al "antiguo peronismo" y advertía del "peligro que representan los extrapartidarios, los compañeros de viaje del peronismo".5 Igual postura tuvo el diario El Popular, dirigido por Jorge Granel también vinculado a los sectores tradicionales del peronismo, que llama a "ponerse la camiseta peronista". 6 El diario nacional La Prensa destacó que los intendentes de Tres de Febrero, San Isidro, Morón, Marcos Paz, General Las Heras y La Matanza se habían reunido con Perón para "revalidarse como justicialistas sin los nuevos rótulos que imponía la campaña macartista de izquierda y de derecha", 7 reforzando el debate alrededor de la identidad política de los ediles que, en la mayoría de los casos, tenían una larga trayectoria en el peronismo.

Como se dijo en el inicio de este apartado, el contexto del inicio del conflicto municipal era el del enfrentamiento entre Montoneros, y los sectores tradicionales del peronismo, el apoyo de Perón a éstos, las acusaciones de infiltración y la persecución política. Sin embargo, las advertencias sobre los "compañeros de viaje" de Heredia y sus compromisos y lealtades políticas dejaron de ser referencia en la prensa local hacia agosto de 1973, cuando la reyerta empezó a mostrarse cada vez más como una disputa entre el intendente y el presidente del Consejo Deliberante (Rubén Novoa) con la intervención eventual del sindicato de empleados municipales.

Entre julio y agosto de 1973 Juan Carlos Ferro, secretario general del COEMA (sindicato de trabajadores municipales), encabezó un reclamo salarial que incluyó también la exigencia de garantizar la estabilidad laboral de los trabajadores del municipio y puso en duda las condiciones de los ascensos que habían mermado en los primeros meses de gobierno. Además, para fines de julio ya había comenzado el conflicto entre el poder legislativo y el ejecutivo del distrito. Con el propósito de solucionar ese enfrentamiento Rubén Novoa, los presidentes de cada bloque, un emisario del sindicato municipal; Hugo Curto (secretario general de la UOM del distrito y representante de las 62 Organizaciones) y Orlando Zicarelli, secretario de gobierno, se reunieron con el Dr. Mariátegui, ministro de gobierno provincial. En esa reunión se pactó garantizar dos encuentros mensuales para solucionar el "problema entre poderes".

Un mes más tarde, la prensa local (especialmente El municipal y Quiénes en la semana, dirigido por Ariedo Bruno Prividor, conectado con los sectores más tradicionales de la política tresfebrerense) daba cuenta de que el conflicto entre poderes continuaba. La expresión del malestar en el Poder Legislativo era manifestada sobre todo por los concejales Rubén Novoa, Carlos Güell, Pedro Gallo, Juan Lerman y Elena Lahia de Cambia contra el Departamento Ejecutivo, al que

\footnotetext{
${ }^{5}$ El Municipal. 19 de marzo de 1973, p. 3.

${ }^{6}$ El Popular, abril de 1973.

${ }^{7}$ La Prensa. 1 de agosto de 1973, p. 14
} 


\section{Luciana Mingrone}

denunciaban como inactivo y con poca actividad para generar expedientes mientras revelaban el atraso en el pago de dietas y en el "acondicionamiento del recinto" del HCD.

Unos días más tarde, los presidentes de cada bloque, Novoa y Zicarelli se reunieron con el gobernador de la provincia, Oscar Bidegain, y el diputado nacional Jorge Mangas, militante justicialista de Tres de Febrero vinculado al Comando de Organización. La reunión destrabó en parte el conflicto, ya que tras ella se aprobó el presupuesto municipal en el Concejo Deliberante. ${ }^{8}$

En septiembre, se produjo la primera interpelación al ministro de gobierno Zicarelli. La prensa local difundió una solicitada firmada por Rubén Novoa en el que se señalaba que la interpelación al ministro de gobierno no había satisfecho al cuerpo legislativo y recomendaba al "Departamento Ejecutivo que se abstenga de adoptar procedimientos que enerven los derechos del sindicato de trabajadores municipales"9, ya que los trabajadores municipales alegaban que había designaciones que contravenían el estatuto municipal y se habían paralizado las promociones y ascensos, aplicando la ley de prescindibilidad.

Fueron pocos los concejales que habían intentado mediar y superar el conflicto. Pablo Ruiz, también dirigente sindical, había propuesto una mesa de negociación que fracasó. Juan Carlos Sandoval apoyó la negociación, pero, sobre todo, denunció que la corrupción era la causa final de todo el conflicto. La mayor parte del bloque justicialista enfrentó a Zicarelli, quién fue interpelado nuevamente algunas semanas después. La segunda interpelación terminó en escándalo y, más tarde, el ministro de gobierno renunció a su cargo.

$\mathrm{Al}$ intervenir en el debate, el subsecretario de gobierno Cleto Falsetti, reclamaba la necesidad de "peronizar el gobierno". En las interpelaciones a Zicarelli, los concejales Carlos Milanesi y Juan Carlos Montes de Oca -miembro también del COEMA- pidieron disculpas si algunas de sus intervenciones habían sido malinterpretadas como dudas respecto a la identidad política peronista del intendente. En las dos interpelaciones que hubo al ministro las "tribunas" se colmaron de afiliados del COEMA para desacreditar al representante del ejecutivo. Pero, como se observa, las alusiones a las identidades políticas de los actores intervinientes parecen más un intento por aprovechar el clima del momento que una reconstrucción exacta de la disputa.

Tras el intento de toma de los cuarteles militares de Azul por parte del Ejército Revolucionario del Pueblo, enero de 1974 fue uno de los momentos cruciales del conflicto entre los sectores más reaccionarios del peronismo y Montoneros, lo que se manifestó en la renuncia a sus bancas de 8 diputados vinculados con la Tendencia y la caída del gobernador de Buenos Aires, Oscar Bidegain, que fue reemplazado por el vicegobernador, el histórico dirigente de la UOM, Victorio Calabró.

\footnotetext{
${ }^{8}$ El deporte en Tres de Febrero, agosto 1973

${ }_{9}^{9}$ Diversos diarios locales, 3 de octubre de 1973.
} 


\section{La primavera que no fue: el gobierno de Roberto Heredia en Tres de Febrero, 1973- 1975}

En ese contexto, el diario Miradas Argentinas enumeraba una serie de "gravísimas acusaciones" contra Heredia. El periódico sentaba posición contra un poder ejecutivo cuya acción se evaluaba como inexistente, mientras se quejaba del mal servicio de recolección de residuos, de subas de impuestos que identificaba como un "asalto a los contribuyentes" e inclusive de que aún no se había cambiado un busto del General Urquiza por uno de Eva Perón como hacía tiempo había solicitado el Concejo Deliberante. El departamento Ejecutivo era calificado como incapaz y se difundía la novedad de que no se había aprobado el presupuesto anual. ${ }^{10}$

Sin embargo, el intendente Heredia logró sortear las álgidas circunstancias de principios de 1974 desvinculándose de las organizaciones armadas y buscando apoyo en el sindicalismo que ahora conducía la provincia. En esos días, Roberto Heredia hizo pública una carta al dirigente sindical, Hugo Curto. En la misiva, el intendente hacía gala de su verticalidad, reclamaba seguir el mandato del general Perón y demandaba la intervención de las 62 Organizaciones, la Juventud Peronista de la República Argentina y la Juventud Sindical. En este particular pedido de apoyo, Heredia resaltaba que las 62 Organizaciones lo habían apoyado antes y que él las reconocía como la "columna vertebral del peronismo". Pero, como vimos, no es la naturaleza del conflicto si no los contextos nacional y provincial lo que explica porque el intendente demandó la intervención de organizaciones juveniles ideológicamente opuestas a los "izquierda peronista" y subrayó el rol de las organizaciones sindicales, cuyo antagonismo con esa militancia juvenil era marcado. En la misma carta, el intendente se comprometía a "reorganizar el elenco de colaboradores", dejando en evidencia que el intendente pretendía rearmar filas entre los sectores tradicionales de su partido.

El intento de Heredia por "desmarcarse" de las organizaciones armadas y la búsqueda de apoyos en el sindicalismo le dio aire al gobierno del atacado intendente que logró sobrevivir en su puesto casi un año más que el resto de los poderes ejecutivos en conflicto. A lo largo de 1974, apareció un paliativo en la disputa entre los diversos sectores del peronismo. Se aprobó un proyecto para cambiar el nombre del partido y, aunque fue por poco tiempo, Tres de Febrero se llamó Juan Manuel de Rosas. $^{11}$

Pero el conflicto se reavivó a fines de 1974. Esta vez, a la crisis iniciada por los entredichos entre el Ejecutivo y el presidente del Concejo Deliberante y las disputas con el sindicato municipal se sumó un nuevo tema de disputa: la obra pública. El diputado Mangas había presentado un proyecto para expropiar unos terrenos conocidos como Dreyfus en las cercanías de la fábrica FIAT, el intendente fue acusado de falta de celeridad para concretar el plan. Además, se adicionaba la interminable construcción del Centro Cívico, cuya licitación se resolvió recién en 1975 con la firma de un acta- convenio entre la municipalidad y la empresa Rimoldi, pero que antes generó una serie de acusaciones de pago de sobreprecios e

10 Miradas Argentinas, 24 de enero de 1974

${ }^{11}$ Numerosos ejemplares de la prensa local lo certifican. 


\section{Luciana Mingrone}

irregularidades en la licitación. En el cenit del conflicto solo los concejales Juan Carlos Rodríguez (Vicepresidente $1^{\circ}$ del Bloque del PJ) y Juan De La Iglesia defendieron la figura del intendente matizando sus posibles errores y adjudicando la crisis a la situación deficitaria heredada del gobierno anterior.

Entre los meses de mayo y agosto de 1975 la prensa local envistió contra Heredia acusándolo de inacción, despreocupación, falta de comunicación con el cuerpo legislativo, "desencanto creciente y pérdida de fe popular" y agregando que la figura lavada de Heredia se explicaba porque "los caudillos quedaron en San Martín".12 La campaña de desprestigio contra Heredia se sobrecargó en junio cuando se lo acusó de adherir al lock-out patronal organizado en esos días porque su panadería había permanecido cerrada aquel día. ${ }^{13}$

Cuando la posición de Heredia era completamente débil se esperaba que el Comando de Organización a través del diputado Mangas terminara de definir la situación. Mangas pretendía lograr la intervención provincial del distrito, pero, sin embargo, la reyerta se resolvió de otra manera: en la séptima sesión ordinaria del HCD en agosto de 1975, Heredia fue destituido y ocupó su lugar Rubén Novoa.

Para Edgardo Fontana, miembro del MR17 y asesor de Juan Carlos Sandoval, fue la honestidad de Heredia lo que le restó apoyo en el PJ e hizo que el concejal lo defendiera. Para ilustrar su postura, Fontana alude a un regalo de la FIAT para miembros del ejecutivo y miembros del Consejo Deliberante que no aceptaron ni Heredia ni Sandoval que siguió recorriendo los barrios populares con su viejo Citröen 2 CV. Esta evocación ofrece pistas para entender la gestión de Heredia y la militancia de Sandoval y la corriente del peronismo revolucionario a la que adscribió.

\section{Segunda parte: La Juventud Peronista en Tres de Febrero}

\section{1- El Movimiento Revolucionario 17 de octubre y su desarrollo local}

Ante los experimentos de "peronismo sin Perón” que promovía -entre otrosAugusto Vandor, a mediados de 1963, Juan Domingo Perón nombró como su delegado personal a Héctor Villalón (adjunto del Comando Superior Peronista) y le pidió que organizara un nuevo espacio. Así nació el Movimiento Revolucionario Peronista, cuya "Declaración de principios" salió a la luz en agosto de 1964 y fue producida por Gustavo Rearte, dirigente de la Juventud Peronista durante la Resistencia, preso CONINTES y creador, en el marco de este nuevo espacio partidario, de la Juventud Revolucionaria Peronista. (Pérez, Ernesto, 2013)

12 Quienes en la semana, mayo 1975.

13 Quienes en la semana, 15 de junio de 1975. 


\section{La primavera que no fue: el gobierno de Roberto Heredia en Tres de Febrero, 1973- 1975}

El MRP alentó la movilización sindical hacia formas de la revuelta fabril y tenía como objetivo la depuración del Movimiento Peronista para que fuera dirigido por una conducción revolucionaria que reorganizara su estructura priorizando los intereses de la clase obrera. En ese sentido, el MRP fue la piedra de toque del peronismo revolucionario en el que confluyeron, antes de conformar la CGT de los Argentinos, los sindicalistas que se oponían al Onganiato, pero también al vandorismo y algunos de los que más tarde fundarían las Fuerzas Armadas Peronista (FAP), la primera guerrilla que asumiría esa identificación política.

Cuando en 1964 Perón confió un intento de retorno a manos del propio Vandor, tomó distancia del MRP hasta 1966, cuando se concretó el golpe de estado de la Revolución Argentina y el dirigente sindical sostuvo una postura partipacionista. Para entonces, Rearte viajó a Cuba, se relacionó con John William Cooke e integró la delegación argentina en la Conferencia de la Organización Latinoamericana de Solidaridad en La Habana. Rearte conservó una buena relación con Perón, que mejoró gracias al estrecho vínculo del joven con el mayor Bernardo Alberte, elegido por el viejo líder como su nuevo delegado personal en 1967.

En 1968, Rearte organizó el primer congreso del peronismo revolucionario con el apoyo de Alberte, representantes de la Acción Revolucionaria Peronista de Cooke, los Comandos Peronistas de Liberación organizados por Juan García Elorrio y sindicalsitas como Jorge Di Pascuale y Julio Guillán. En esas circunstancias, nació la primera Tendencia Revolucionaria del Peronismo, influida por las ideas "tendencistas" de Cooke y la noción de vanguardia revolucionaria que él desarrolló, pero también defensora del foquismo, a pesar del cercano fracaso de las FAP en Taco Ralo. (Gurucharri, Pérez, Fontana, Alfaro, 2020)

En 1970, la JRP rompió con el MRP y dio origen al Movimiento Revolucionario- 17 de octubre (MR17). El 1 de julio de 1973 Rearte murió y la conducción del MR17 quedó a cargo de un colectivo de 8 personas entre los que estaba Pedro Sandoval. Pedro, que era el hermano de Juan Carlos el concejal tresfebrerense, había estudiado en la Escuela de Mecánica de la Armada y renunció a su puesto como obrero naval para trabajar en Sudamtex y militar en el JRP.

El 25 de mayo de 1975, el MR-17 formaría junto al Frente Revolucionario Peronista una organización cuyos referentes eran Juan Carlos Arroyo y Armando Jaime, el Frente Revolucionario 17 de octubre. Pedro Sandoval también integró el comité de unificación de estos dos espacios. El FR17 nacería así a instancias de la estrategia que Gustavo Rearte había propuesto poco antes de su muerte y que tenía como fin último configurar una construcción política amplia en la que confluyeran todos los espacios políticos del alternativismo, aquellos que se identificaban con el peronismo, pero sugerían una instancia superadora por fuera del partido y de la referencia al líder y sus dirigentes históricos.

En 1975, las palabras de Pedro Sandoval cerraron el congreso del FR17 y en ellas el entrerriano señaló que si las diferentes organizaciones del peronismo revolucionario no habían podido confluir antes en un único espacio era porque, durante la década de 1960, el MRP incluía estrategias que priorizaban los intereses 


\section{Luciana Mingrone}

de la clase obrera, pero "la táctica la implementaba Juan Perón y la instrumentaba en función de su propio interés y en función de su propia política” y agregó que en esos años ellos no podían escapar de esa influencia pero, habiendo "aprendido de los errores" y asumido "necesidad de la ideología", comprendían la urgencia de la construcción de un partido "sobre bases marxistas con elementos leninistas" en el que confluyera toda la izquierda revolucionaria, para interesar a las masas y "convertirnos en destacamento de avanzada de la clase obrera para llevar adelante la revolución socialista", cerró el entrerriano. ${ }^{14}$

Los hermanos Pedro y Juan Carlos y toda la familia Sandoval -especialmente el papá Felipe y la hermana mayor, Susana- tenía una profusa militancia en la Resistencia Peronista y su carpintería se transformó en lugar de reunión de la pequeña célula que luego sería la Agrupación 9 de junio. Los Sandoval acompañaron a Rearte en la JRP y también en la escisión que configuró el MR17. En lo local, esa construcción nació en un ámbito asambleario: "en un plenario en el departamento del tío Sixto que estábamos el gordo Marcelo (Juan Carlos Sandoval) y su mujer, Goyo, Coco, Pati, Mari, Pepe, Tito, Sixto, yo, Susana Sandoval y Pedro a mediados del 71, ahí nace la Agrupación 9 de junio", testimonia Edgardo Fontana. Esa agrupación pretendió articular el trabajo político de parte de los militantes del MR17 en el distrito. Desarrolló un profundo trabajo de inserción de masas, recorriendo los barrios populares, trabajando junto a los vecinos y elaborando estrategias vinculadas, también, con las luchas obreras en varias fábricas locales. Juan Carlos Sandoval se transformó en referente de la UB "9 de Junio" en Caseros. Además, la agrupación tenía un local en "Villa Perdida" y en el centro de la Villa Paris. El activismo de la familia Sandoval en el peronismo revolucionario del distrito era protagónico: una de las UB del popular Barrio Derqui se identificaba con el Peronismo de Base y uno de sus referentes era Gerardo Sandoval, que en 1976 se uniría al ámbito sindical del FR17.

El MR17 tenía especial actividad en las fábricas y los pequeños talleres de la zona. Entre sus trabajadores se repartía el periódico "El cumpa" que contaba experiencias de lucha fabril y difundía opiniones de obreros. En 1975, el MR17 de Tres de Febrero formó la Regional Norte junto con San Martín, General Sarmiento y parte de la militancia de Vicente López, Munro y Florida, zona en la que luego organizarían las coordinadoras fabriles alrededor de la que funcionó en FIAT. La conducción y los militantes del MR17 se preocuparon especialmente por diferenciar su tarea en los barrios y las fábricas de las operaciones militares, entre las que tuvo notoriedad la voladura de varios autos en una importante concesionaria de una marca multinacional. ${ }^{15}$

La base de acción del movimiento fue la Unidad Básica Felipe Vallese de Pablo Podestá y la Sociedad de Fomento Martín Güemes del Barrio Manzanares en Villa Bosch a cuyos vecinos los militantes de la agrupación ayudaron a instalar cloacas y

${ }^{14}$ El discurso fue citado sin referencia a Sandoval en el número 21 del periódico En lucha de abril de 1975. La autoría de Sandoval se detalla en Eduardo Gurucharri et al (2020), pp. 275-277.

${ }^{15}$ Edgardo Fontana en entrevista con la autora, febrero 2012. 


\section{La primavera que no fue: el gobierno de Roberto Heredia en Tres de Febrero, 1973- 1975}

servicios. Sixto Salgueiro se terminó convirtiendo en el referente de esa Sociedad de Fomento.

El máximo referente del MR17 de octubre, Gustavo Rearte, tenía posturas opuestas respecto a su integración institucional al PJ. En 1972 Rearte rechazó en Madrid el ofrecimiento de formar un "tridente de trasvasamiento generacional" junto a Rodolfo Galimberti y Julián Licastro pero en el contexto de la apertura democrática miró con recelo la posibilidad del retorno de Perón. También Bernardo Alberte, que había articulado con Rearte en el Movimiento Revolucionario Peronista, se lo señaló al viejo general a través de una misiva, advirtiéndole sobre la "índole tramposa de las elecciones": "Se trata de crear un gobierno que siga con la obra del actual (...) no hay posibilidad alguna de gobernar determinando el empobrecimiento del pueblo y la colonización del país sin ejercer simultáneamente una dictadura, por eso el carácter crecientemente dictatorial del régimen. Por ello, es increíble observar con qué superficialidad e irresponsabilidad se está planificando todo un operativo para trasladar de lugar el Comando Estratégico del Movimiento, concretamente el "operativo retorno" (...) Ese Perón conciliador y entregado no existe y es una posibilidad irreal y arbitraria, creación de la infamia oligárquica. Perón no puede pacificar al país, si no después de la destrucción del enemigo." Y ratifica que "la estrategia del peronismo no debe ser otra que la guerra popular prolongada" (Gurucharri, Pérez, Fontana, Alfaro, 2020, 141: 142)

Como congresal, Gustavo Rearte tomó la palabra en el Congreso del PJ de diciembre de 1972 e instó a sostener la candidatura de Perón exigida desde agosto y formar un verdadero frente nacional que se diera un programa antiimperialista. Rearte y el resto de la militancia del MR-17 manifestaron abiertamente su negativa a la consolidación de la alianza electoral y la candidatura de Cámpora, sin embargo, participaron activamente de la campaña electoral. El MR17 como organización intentó participar en el juego democrático en muchos lugares: en La Matanza logró concejales y secretarios como Honorio Gutiérrez (UTA) y Delfor Soto. Tal intervención en la actividad electoral se decidió en un plenario: la agrupación existía en Lomas de Zamora, Lanús, Almirante Brown, Merlo, La Plata, Morón, San Martín, Gral. Sarmiento y en la Ciudad de Buenos Aires, donde Ismael Chukri -miembro de la Agrupación 9 de junio- participaba de la mesa directiva del Partido Justicialista. La apertura democrática generó un enorme debate también a nivel local: "ahí empezamos a pensar que había que pelearle los puestos al PJ porque se iba a abrir",16 recuerda Fontana. Pedro Sandoval consideraba que "lo electoral llevaba al fracaso y que nos abría al enemigo, él pensaba más en sostener una organización",17 pero su hermano Juan Carlos apoyaba la salida electoral, de allí que fuera candidato a concejal. Hacia fines de 1972 la agrupación local primero "negoció" con Heredia en algunos encuentros en su panadería y luego sostuvo cuatro reuniones con diferentes

16 Edgardo Fontana en entrevista con la autora, febrero 2012. Al tiempo de asumir su banca, Sandoval integró a Fontana como parte de su equipo cuya función era recorrer los barrios, vincular al concejal con los vecinos y que las problemáticas populares tuvieran resonancia en el Concejo Deliberante.

17 Edgardo Fontana en entrevista con la autora, febrero 2012. 


\section{Luciana Mingrone}

sectores del justicialismo y el sindicalismo en la sede de la Unión Ferroviaria de Santos Lugares, en una Unidad Básica en la Avenida América cerca de la estación Sáenz Peña y, finalmente, en la sede local de la UOM. "Goyo", Juan, Sixto y Fontana encabezaron estas reuniones, en las que no faltaron violentos cruces con algún miembro del $\mathrm{CdeO}$ y Guardia de Hierro, espacios claves de la joven militancia peronista en el distrito. Los jóvenes lograron un espacio en las listas de concejales que inicialmente le fue ofrecido a Josefina Thompson ${ }^{18}$ quién señaló que el ungido debía ser Juan Carlos Sandoval por su inserción en los barrios populares del distrito. Sandoval fue el candidato número 17 y Thompson la primera candidata suplente. Los militantes que centraban su trabajo en la UB Felipe Vallese (cuyos referentes eran Salgueiro y Remo Urquiza) participaron activamente de la campaña electoral e invitaron al candidato Heredia a recorrer Pablo Podestá y otros barrios en los que tenían inserción.

La victoria electoral del FREJULI fue tan contundente que se conformó un bloque de 17 concejales, convirtiendo a Sandoval en uno de ellos. En su asunción Sandoval juró por los "compañeros caídos desde 1955", lo que lo diferenció tanto de sus compañeros que se instaló la idea de que el FREJULI tenía "16 concejales y Sandoval".

\section{2- Los contactos entre el MR17 y Montoneros en Tres de Febrero}

En 1969 las convulsionadas jornadas de protesta en Córdoba, Rosario, Chaco, hicieron que un sector del Movimiento Revolucionario Peronista y su juventud, rompiera con la organización al abandonar su postura foquista e intentar combinar la política de masas y la teoría revolucionaria, en una organización armada por fuera de la estructura partidaria: así, el MR17 surgió de esas reflexiones. Como se sabe, Montoneros había seguido un camino parecido y encontrado en la noción de vanguardia esgrimida por John William Cooke una articulación que le permitió pensar en la conducción de las masas por el camino de la revolución.

La ruptura entre el MR17 con el MRP en 1970 tuvo que ver en buena medida con el rol que Villalón (que había conocido Cooke en Cuba con quién conservaba pésimas relaciones) le daba al espacio como herramienta para promover la lucha por el regreso de Perón. Cooke, en cambio, había tenido influencia sobre el propio Rearte acerca de la necesidad de gestar una vanguardia revolucionaria. El documento matriz del pensamiento del MR17, "Violencia y tarea principal", escrito por Gustavo Rearte, sentó las bases de cómo la organización se pensó a sí misma y su relación con el peronismo, de cuyo seno había nacido:

"Acción política y lucha armada constituyen aspectos indivisibles de un mismo y único proceso en el que se forjan organización política y fuerzas armadas; pero de su planteamiento resulta una contradicción de la cual, la necesidad de construir un

${ }^{18}$ Liliana y Josefina Thompson eran militantes de diversos espacios de la militancia juvenil peronista del distrito, Liliana del Comando de Organización y Josefina del Peronismo de Base, del PB 17 de octubre y, en 1975, del FR17. 


\section{La primavera que no fue: el gobierno de Roberto Heredia en Tres de Febrero, 1973- 1975}

mínimo de vanguardia, surgida de la lucha popular y orgánicamente unida a ella en torno a una política que se construye en una relación constante con las bases populares". ${ }^{19}$

Como puede deducirse del citado documento de Rearte, la participación de Juan Carlos Sandoval y de otros militantes del MR17 en instancias electorales y, eventualmente, en cargos públicos está más vinculada con la posibilidad de ganar espacios dentro del peronismo que con la puesta en marcha de políticas públicas que pudieran contribuir a la construcción de la "patria socialista". En el caso de Sandoval, es claro que la centralidad de los hechos relatados en este trabajo fue clave para que la gestión de Heredia se viera absolutamente obturada y no pudiera desarrollarse ningún proyecto político. Pero, además, si pensamos en las políticas no armadas que el MR17 implementó en el distrito la prioridad estuvo en la activación fabril y territorial antes que en la administración pública y, fue, por cierto, mucho más extensiva, duradera y sostenida que cualquier operación militar.

En oposición a esta combinación de prácticas políticas del MR17, la militancia montonera del distrito (cuya articulación local en 1973 era muy incipiente) privilegió el trabajo en los barrios populares como herramienta de inserción territorial y ampliación de su ascendencia popular. Además, una cantidad de diferencias programáticas vinculadas con la noción de vanguardia y el rol de la organización político- militar como articulador de los intereses de la clase trabajadora distanciaron al MR17 y a Montoneros. Pero, en la experiencia local, unos y otros compartieron espacios de socialización desde el período de gestación de ambas organizaciones. En el Instituto La Merced habían confluido los Fontana y un grupo de compañeros que formaron allí un grupo Scout en 1967 con el padre Mario Bertone, un cura que adhería a la corriente de los Sacerdotes para el Tercer Mundo. En 1969, Bertone y su grupo iniciaron el proyecto de instalar una capilla en lo que se conoce como el barrio Fiat, donde estaba la vieja fábrica de autos, en los alrededores de la actual Citröen- Peugeot. Ahí formaron un nuevo grupo scout y comenzaron a trabajar sobre la construcción de la capilla San Francisco de Asís. En ese espacio, desarrollaron un trabajo social de vinculación con la comunidad a partir del Concilio Vaticano Segundo y de la integración de los sacerdotes a las comunidades con una relación que no era exclusivamente religiosa. Con las limosnas y aportes personales de los jóvenes, se levantó la capilla San Francisco de Asís y se ayudó a los vecinos del precario barrio obrero a construir, reparar o mejorar sus viviendas. El padre Bertone abandonó los hábitos en 1972, se casó y dejó la parroquia y fue funcionario del gobierno de Bidegain.

Edgardo Fontana y su hermana Liliana (futura esposa de Pedro Sandoval), también expulsados de La Merced, continuaron sus estudios en Colegio José Hernández (Escuela Media $\mathrm{N}^{\circ}$ 3), dónde iniciaron el "Movimiento estudiantil Secundario Eva Perón". A través de ese espacio de militancia estudiantil los hermanos Fontana intentaron formar la Unión de Estudiantes Secundarios en el distrito, para lo que

${ }^{19}$ Versión completa del documento "Violencia y tarea principal” en Pérez, 2003, pp. 145- 147 


\section{Luciana Mingrone}

entraron en contacto con jóvenes militantes del Instituto Ceferino Namuncurá y la Escuela de Educación Media $\mathrm{N}^{\circ} 2$ (Bernardino Rivadavia). Sin embargo, en este primer ensayo de UES planearon no integrarse a Montoneros sino armar una organización amplia y abierta. Más de la mitad de la militancia de estudiantes secundarios de la zona -concentrada fuertemente en las medias 2 y 3- rechazaron la integración a la UES. Los Fontana confluirían en la célula primigenia del MR17 en la zona y harían de la Sociedad de Fomento Martín Fierro y la militancia en el barrio Manzanares uno de sus principales centros de acción.

Resulta llamativo que una organización de la sociedad civil más asociada a otras tradiciones políticas, como una sociedad de fomento, haya sido el espacio de sociabilidad y activación política de dos organizaciones diversas de la "izquierda peronista". Además de los miembros del MR17, en la sociedad de fomento del Barrio Manzanares se congregaron algunos jóvenes que provenían de grupos católicos vinculados con el Instituto Pío XII de Villa Bosch. Urbano López y María del Carmen Luppo, por ejemplo, se habían conocido en ese ámbito y habían comenzado a militar en una unidad básica dirigida por los hermanos Sielinsky, míticos integrantes del CdeO local. Influidos por Víctor Mariani -un sociólogo vinculado con agrupaciones juveniles del peronismo-, Urbano y "Mary" abandonaron aquel espacio y formaron (junto con otros militantes) la Unidad Básica John William Cooke, en Villa Bosch. Fue Mariani quien en 1972 se reunió con "Coco" para conformar la célula montonera local y, así, se inició el proceso de integración de los miembros de la UB Cooke a la organización. ${ }^{20}$

"Coco", un militante de Descamisados, maestro de zona Norte que trabajaba en una escuela de Flores, pero se instaló en Ciudadela como responsable de Montoneros durante la gestación del grupo en la zona y fue quien se vinculó con estructuras que tenían militancia previa allí. Además del grupo de "scouts" de Barrio FIAT y los jóvenes de la UB Cooke de Villa Bosch, "Coco" articuló en Montoneros una UB de Ciudad Jardín y otra cercana a la Basílica de Lourdes que funcionó como cabecera de la organización durante la campaña electoral y en la que se destacaba Rodolfo Raúl "Cañita" Rey, reconocido por testimonios como el "primer militante montonero" del distrito. "Cañita" participó del Operativo Dorrego y la Unidad Básica de Santos Lugares también sirvió de base para la organización de voluntarios de esa operación que Montoneros articuló con las FFAA. En 1974 (con la instalación de los vecinos trasladados por el plan de erradicación de la "Villa 31" de Retiro en el barrio que hoy se estigmatiza como "Fuerte Apache" y que entonces se bautizó "Barrio Liberación, Carlos Mugica) se sumó un grupo que conformó el Movimiento Villero Peronista local. ${ }^{21}$

Si analizamos los procesos de politización constatados en estos jóvenes, es decir, si intentamos una lectura sobre cómo estos actores articularon sus demandas y prácticas políticas en un proyecto más amplio, hay que decir que allí también ese

${ }^{20}$ María del Carmen Luppo y “Coco" en entrevista con la autora, febrero 2017.
21 "Coco" en entrevista con la autora, 2017. 


\section{La primavera que no fue: el gobierno de Roberto Heredia en Tres de Febrero, 1973- 1975}

proceso conllevó a una variedad de resultados. No todos los militantes del grupo scout, por ejemplo, se "peronizaron" ni adhirieron a Montoneros, algunos de ellos militaron en la Federación Comunista y otros solo activaron en la UES. Y, si bien en la mayoría de los casos su ámbito de militancia siguió siendo el barrial, algunos como José Manuel Pérez Rojo (jefe militar de la Columna Oeste de Montoneros), protagonizaron un vertiginoso proceso de radicalización.

Sin embargo, es importante destacar dos cosas: por un lado, que Montoneros privilegiara la inserción territorial en los barrios populares del distrito obedece a que pensaba ese ámbito como una vía para la ampliación de sus bases de apoyo político (especialmente durante la campaña "Luche y vuelve" y en los sucesivos eventos de movilización masiva que acompañaron la apertura democrática). Al mismo tiempo, esta práctica política no armada convivió con la lógica militar y fue paralela a la consolidación del proceso de radicalización (el desarrollo conjunto de la lucha armada y las prácticas políticas no violentas es uno que puede verse en otros casos como el de Mar del Plata según Pozzoni, 2008 y Bartolucci, 2017).

\section{Consideraciones finales}

Este trabajo es apenas el incipiente germen de una tarea de más amplio desarrollo cuyo fundamento radica en la certeza de que los estudios de caso y las historias locales contribuyen a comprender profundamente un período sumamente vertiginoso. Aunque varias veces se ha tratado el caso de las provincias intervenidas por el gobierno nacional entre 1973 y 1974 a instancias de enfrentamientos entre el peronismo tradicional, el sindicalismo burocrático y Montoneros, pocas veces se estudiaron los gobiernos distritales en los que se sufrieron procesos parecidos. Este trabajo echó algo de luz sobre uno de esos casos: el de Tres de Febrero.

En este esbozo se pudo ver que el aparente conflicto ideológico fue sobre todo una interna palaciega y que las acusaciones sobre la vinculación del intendente Heredia con Montoneros fueron una estrategia más vinculada con el discurso público que con la propia construcción política del mandatario municipal. Asimismo, se corroboró que esa construcción rozó apenas otra vertiente de radicalización política gestada aún antes que Montoneros: el Movimiento Revolucionario 17 de octubre.

Finalmente, en el acercamiento a ese espacio se pudo poner la lupa sobre la capilaridad de la red constituida por los cruces y bifurcaciones entre Montoneros y el MR17 a nivel local, con diferencias programáticas sustanciales y trayectorias diversas, pero espacios de prácticas políticas compartidas. Está claro que, en 1975, los descendientes de la Resistencia Peronista y fundadores de la primera Tendencia Revolucionaria crearon una "alternativa independiente" en la que no pudieron convivir con quienes había apostado a la segunda tendencia, pero esos fueron los resultados de un vertiginoso proceso. Antes, y especialmente desde la apertura electoral hasta el regreso a la clandestinidad de Montoneros en 1974 su militancia de base compartió espacios de sociabilidad y actividad política, caminos de 


\section{Luciana Mingrone}

politización que en muchas ocasiones tuvieron un origen común (la escuela) y que en la mayoría de los casos tendría también el mismo fin como víctimas del terrorismo de Estado, como los propios Juan Carlos Sandoval y Teresa Elvira Thompson, concejales del MR17 durante el gobierno del peronista Roberto Manuel Heredia.

\section{Bibliografía}

Abbatista, M. L. y F. Tocho, (2012). “El verano caliente del '74. La Tendencia Revolucionaria del peronismo entre la asunción de Perón y aniversario del 'triunfo popular'" ponencia presentada en VII Jornadas de Sociología de la UNLP.

Acha, O. (2011). Los muchachos peronistas. Los orígenes olvidados de la Juventud Peronista (1945-1955). Buenos Aires: Planeta.

Antúnez, D. (2015). "El peronismo en los municipios bonaerenses de 1973- 1976" en Coordenadas. Revista de historia local y regional. Año II, $\mathrm{N}^{\circ} 1$.

Asociación Familiares y compañeros de detenidos- desaparecidos de Tres de Febrero. Gacetillas, investigaciones y reconstrucciones de biografías. Disponibles en www.memoriatresdefebrero.com

Bartolucci, M. (2017). La juventud Maravillosa. La peronización y los orígenes de la violencia política, 1958-1972. Sáenz Peña: UNTREF.

Bozza, J. (1997). "Perón y el Frente Cívico de Liberación Nacional: Coalición y confrontación" [En línea]. Cuadernos del CISH, 2(2-3). Disponible en: http://www.fuentesmemoria.fahce.unlp.edu.ar/art revistas/pr.2637/pr.2637.pdf.

Caruso, V.; E. Campos, M. Vigo y 0. Acha. (2017). “Izquierda peronista: una categoría útil para el análisis histórico" en Historiografías, 14, pp. 68-90.

De Riz, L. (2002, primera edición 1986). La política en suspenso 1966/1976. Buenos Aires: Paidós.

Ehrlich, L. (2012). "Los espacios de sociabilidad en la estructuración de la Juventud Peronista post 55 en la Ciudad de Buenos Aires" en Apuntes de investigación del CECYP. Año $16 \mathrm{~N}^{\circ} 21$

Ferrari, M. y Pozzoni, M., (2009). "De la interna a la Legislatura: los enfrentamientos en el peronismo bonaerense, 1973-1976". Ponencia presentada en las XII Jornadas Interescuelas/Departamentos de Historia. 


\section{La primavera que no fue: el gobierno de Roberto Heredia en Tres de Febrero, 1973- 1975}

Franco, M. (2012). Un enemigo para la nación. Orden interno, violencia y "subversión". 1973- 1976. Buenos Aires: FCE.

Friedemann, S. (2018). “La izquierda peronista de los años sesenta como fenómeno argentino de la llamada nueva izquierda" en Tempo e Argumento, Florianópolis, v. 10, n. 24, p. $484-509$.

Gillespie, Richard (1987) Soldados de Perón. Los Montoneros. Buenos Aires: Grijalbo.

González Canosa, M. y M. Chama (2018). "Activación social, politización y radicalización. Reflexiones sobre sus usos y sentidos en la producción académica sobre los sesentas-setentas en Argentina" XXXVI Congreso Internacional del Latin American Studies Association (LASA). Lugar: Barcelona

González Canosa, M. y J. Murphy (2019). “De los corsos, los sindicatos, el fútbol y la "resistencia" a la vuelta de Perón. Orígenes y gestación de la Juventud Peronista de Rawson (1969- 1972)" en Coordenadas. Revista de historia local y regional. Año VI, Número 1.

Gurucharri, E.; J. Pérez, E.Fontana y S. Alfaro. (2020). La patria socialista. Una historia de la corriente del peronismo revolucionario. MRP, JRP, FRP, MR17, FR17. Buenos Aires: Ediciones en lucha.

Ladeuix, J. (2005). “Entre la institucionalización y la práctica. La normalización del Partido Justicialista de la provincia de Buenos Aires. 1972- 1973" disponible en http://www.unsam.edu.ar/escuelas/politica/centro historia politica/material/15 7.pdf

Lanusse, L. (2005). Montoneros: el mito de sus doce fundadores. Buenos Aires, Vergara.

Leiva, 0. "Política nacional y escala local. Las luchas y divisiones del tercer peronismo en Pergamino (1973-1976)" disponible en www.riehr.com.ar

Mellado, M. V. (2009) "Los trazos de la disgregación: el juicio político al gobernador Martinez Bacca, Mendoza 1973-1974” en Quinto Sol, № 13, pp. 125-150. Disponible en htp://sociohistoricos.files.wordpress.com/2010/06/13-mellado.pdf

Merele, H. (2017). La “depuración” ideológica del peronismo en General Sarmiento (1973- 1976). Una aproximación al proceso represivo durante los años stenta constitucionales a partir del caso de Antonio 'Tito' Delereoni. Buenos Aires: UNLP, UNGS.

Moyano, M. J. (1995). Argentina's lost patrol. Armed struggle. 1969- 1979. New Heaven: Yale University Press. 


\section{Luciana Mingrone}

Ollier, M. M. (2005). Golpe o revolución. La violencia legitimada, Argentina 1966/ 1973. Caseros: Eduntref.

Pérez, E. D. (2013). MR17- FR17. Historia de una organización político- militar. Tesis de licenciatura, FFyL, UBA.

Pozzoni, M. (2008). "La cultura juvenil. Un estudio de caso: Mar del Plata, 19721976" en historiapolitica.com, $3^{\circ}$ Jornadas sobre la Política en Buenos Aires en el siglo XX.

Robles, H. (2011). "Radicalización política y sectores populares en la Argentina de los años '70: la Juventud Peronista y su articulación con Montoneros en los barrios periféricos de la Ciudad de La Plata" en http://www.memoria.fahce.unlp.edu.ar/library?a=d\&c=tesis\&d=Ite437

Salcedo, J. (2011). Los Montoneros del barrio. Caseros: Eduntref.

Servetto, A. (2010). 73/ 76 El gobierno peronista contra las "provincias montoneras". Buenos Aires: Siglo XXI Editores.

Slipak, D. (2015). Las revistas montoneras. Cómo la organización construyó su identidad a través de sus publicaciones. Buenos Aires: Siglo XXI ed.

\section{Fuentes}

Diarios zonales: Hechos, Sucesos sanmartinenses, El Popular, José E. Ingenieros, Mundo mejor, Mirador argentino, El Municipio, El Mirador, La voz de Ciudadela.

Testimonios: Cristina Heredia, Edgardo Fontana, Oscar Velaz, María del Carmen López, “Coco”, Máximo Rodríguez.

Recibido: $15 / 07 / 2020$

Evaluado: $10 / 08 / 2020$

Versión Final: 02/10/2020 